\title{
The natural history of euthyroid multinodular goitre
}

\author{
J.W.F. Elte, ${ }^{1,2}$ J.K. Bussemaker' ${ }^{1}$ and A. Haak ${ }^{1,3}$ \\ ${ }^{1}$ Department of Endocrinology, University Hospital, Leiden, ${ }^{2}$ Department of Internal Medicine, Sint \\ Franciscus Gasthuis, Rotterdam and ${ }^{3}$ Department of Internal Medicine, Diakonesseninrichting Bronovo, \\ The Hague, The Netherlands
}

\begin{abstract}
Summary: In this communication data on the natural history of euthyroid multinodular goitres are presented. From a total group of 140 patients (mean age 54.6 years, 14 men and 126 women; 88 with autonomous, 52 with non-autonomous function), follow-up data were available for 90 patients (mean age 54.0 years, 11 men and 79 women; 64 with autonomous, 26 with non-autonomous function). During follow-up (means: 5.0 years, maximum 12.2 years) transitions in function were seen 15 times; 8 autonomous patients became hyperthyroid after $<1-7$ years. There were 6 transitions from non-autonomy to autonomy and 1 from autonomy to non-autonomy. One patient who demonstrated the whole cycle from non-autonomy through autonomy up to hyperthyroidism is described in more detail. In one patient operated upon because of hyperparathyroidism a follicular carcinoma was found by chance. Mechanical problems were the reason for surgery in 6 patients only, 16 patients were operated upon because of cosmetic reasons (mostly in the early years of the study). Finally, results from 19 TRH tests in 16 autonomous patients suggest that TRH tests in patients with autonomously functioning euthyroid multinodular goitres are not yet redundant.
\end{abstract}

\section{Introduction}

Early studies concerning the natural history of multinodular goitre mainly dealt with the risk of carcinoma,${ }^{1-3}$ although the development of hyperthyroidism in a non-toxic nodular goitre was recognized. ${ }^{4.5}$ More recently articles have reported long-term follow-up of patients with solitary autonomously functioning thyroid nodules ${ }^{6-10}$ and with respect to the development of hyperthyroidism.

Transversal studies suggest that the frequency of functional autonomy in multinodular goitres increases with age. ${ }^{11-14}$ A stage of hyperthyroidism seems to be preceded by a stage in which the thyroid functions autonomously (impaired thyrotrophin [TSH] response on thyrotrophin releasing hormone [TRH] and/or decreased triiodothyronine $\left[\mathrm{T}_{3}\right]$ suppression) but produces a normal amount of thyroid hormones.

Few longitudinal studies have been carried out on the natural history of sporadic non-toxic nodular goitre, most of the data coming from The Netherlands. ${ }^{15-17}$. In this communication followup data over a maximal period of approximately 10 years from 90 patients with euthyroid multinodular goitre are presented.

Correspondence: J.W.F. Elte, M.D., Sint Franciscus Gasthuis, Kleiweg 500, NL-3045 PM, Rotterdam, The Netherlands

Accepted: 5 October 1989

\section{Patients and methods}

Ninety patients ( 79 women) with a mean age of 54.0 years of whom 64 had autonomous and 26 nonautonomous euthyroid function underwent followup investigation for a mean duration of 5 years. In the first 2 years of follow-up 11 of these 90 patients were operated upon. Seventy one patients (52 autonomous, 19 non-autonomous) underwent repeated TRH testing during the follow-up period. Patients mostly had follow-up investigations on regular outpatient visits, but 10 patients who had not shown up for several years were called up for re-examination. Of these 10 patients 4 did not come.

The 90 patients were derived from a total group of 140 euthyroid patients (mean age 54.7 years, 126 women), 88 of whom had autonomous and 52 non-autonomous thyroid function. Thirty six patients did not show up again after the first examination and 14 were operated upon within 2 months, mainly for unclear reasons. Thus 50 patients in total had no follow-up investigations.

Autonomy was defined as a TSH response ( $\triangle \mathrm{TSH}$ ) of less than or equal to $4.0 \mathrm{mU} / 1$ after the i.v. administration of $200 \mu \mathrm{g}$ TRH. For TSH values $<1.0$ an arbitrary figure of 0.5 was used for calculation of $\Delta T S H$. In the beginning also $T_{3}$ suppression tests were performed. A decrease in the 24-hour radio iodine uptake after $T_{3}$ administra- 
tion (100 $\mu \mathrm{g}$ daily orally for 8 days) of less than $50 \%$ of the basal uptake was considered a criterion of autonomy. ${ }^{2}$

Multinodularity was established on the basis of palpation and/or scintiscans. Thyroid function was evaluated on the basis of clinical data, tracer measurements (in the early years), serum thyroxine $\left(T_{4}\right)$ (reference values: $65-160 \mathrm{nmol} / 1$ ), serum $T_{3}$ (reference values: $1.0-3.1 \mathrm{nmol} / 1$ ) and $T_{3}$ resinuptake $\left(\mathrm{RT}_{3} \mathrm{U}\right)$ (reference values: $22-33 \%$ ). Serum $T_{4}, T_{3}$ and $R_{3} T_{3}$ were determined with commercially available kits; Free $T_{4}$ index $\left(\mathrm{FT}_{4} \mathrm{I}\right)$ was calculated by multiplying $T_{4}$ and $R T_{3} U$ divided by 100 ; Free $\mathrm{T}_{3}$ index $\left(\mathrm{FT}_{3} \mathrm{I}\right)$ was calculated by multiplying $T_{3}$ and $R T_{3} U$. Serum $T S H$ was measured with a RIA-kit (reference values: basal $<1-5 \mathrm{mU} / 1$ ); from June 1985 the highly sensitive time-resolved fluorometric assay of LKBWallac was employed. Sensitivity $0.04 \mathrm{mU} / 1$ and interassay variation $<5 \%$. Reference values with $95 \%$ confidence limits in healthy persons: $0.20-4.0 \mathrm{mU} / 1$, median level $0.80 \mathrm{mU} / 1$. Standards were calibrated against international reference preparation WHO 68/38.

From 19 TRH tests, performed in 16 patients with autonomously functioning euthyroid goitres, in which a sensitive TSH-assay was used, data were statistically processed to evaluate whether the TRH tests could have been replaced by a basal TSH measurement only.

For statistical assessment regression analysis was employed and correlation coefficients were calculated.

\section{Results}

Table I shows the events observed, in relation to length of follow-up and thyroid function.

Changes in thyroid function were observed in 15 patients. Hyperthyroidism developed in 8 patients, all but one of whom had autonomous function initially. One of these patients had $\mathrm{T}_{3}$-toxicosis. Six patients changed from non-autonomous to autonomous function. One autonomous patient returned to non-autonomous function. Two other patients showed fluctuating responses in the TRH test. One patient who had non-autonomous function at the start, became autonomous later on and ultimately hyperthyroid.

Only one follicular carcinoma was found by chance in a patient operated upon because of hyperparathyroidism. This patient had undergone neck irradiation in her youth and a previous operation 24 years before because of a follicular adenoma. Two patients were operated upon because of a cold nodule, which proved to be benign.

Twenty two patients underwent surgery, especially in the early years (1975-1976) of this study, mainly because of cosmetic reasons; in only 5 patients were mechanical complications the apparent reason for surgery.

From June 1985 a sensitive immunofluorometric TSH-assay was employed. Nineteen TRH tests performed in 16 patients with autonomously functioning goitres were statistically assessed. Basal serum TSH values were unmeasurably low in 3

Table I Developments during follow-up in 90 patients with multinodular goitre, initially euthyroid

\begin{tabular}{lccc}
\hline $\begin{array}{l}\text { Duration of } \\
\text { follow'-up (years) }\end{array}$ & $\begin{array}{c}\text { Total no. of } \\
\text { patients }\end{array}$ & $\begin{array}{c}\text { Thyroid surgery } \\
\text { because of mechan. } \\
\text { complic/cosmetic }\end{array}$ & $\begin{array}{c}\text { Hyper- } \\
\text { thyroidism }\end{array}$ \\
\hline$<1$ & $10(8)$ & $6(3)$ & $2(2)$ \\
$1-<2$ & $10(8)$ & $5(4)$ & $1(1)$ \\
$2-<3$ & $7(5) \dagger$ & & $1^{*}(1)$ \\
$3-<4$ & $7(5)$ & $4(4)$ & \\
$4-<5$ & $13(8)$ & $3(2)$ & $2^{* *}(2)$ \\
$5-<6$ & $4(2)$ & 1 & $1(1)$ \\
$6-<7$ & $11(7)$ & $1(1)$ & $1(1)$ \\
$7-<8$ & $11(9)$ & $1(1)$ & \\
$8-<9$ & $12(9)$ & $1(1)$ & \\
$9-<10$ & $4(3)$ & & \\
12.2 & 1 & $22(16)$ & \\
Total & $90(64)$ & & \\
\hline
\end{tabular}

() autonomous; † One patient had follicular carcinoma (see text). *Patient with $\mathrm{T}_{3}$ toxicosis; **1 patient who was euthyroid nonautonomous originally, became autonomous and eventually hyperthyroid 
patients. No correlation was found when basal TSH and $\Delta$ TSH were compared (Figure 1).

The one patient who exhibited the whole cycle of non-autonomous function through autonomy to hyperthyroidism is described in detail.

\section{Case report (Figure 2)}

A female patient, born in 1947, was seen for the first time in 1973 because of a diffuse goitre without palpable nodules. The protein bound iodine was normal. The mother of the patient was known to have multinodular goitre and was also included in our study in 1978. In 1979 she had a multinodular goitre, which was confirmed by scintigraphy and later also by ultrasonography. Thyroid function including the TRH test was normal. Over the subsequent years the serum $T_{4}$ and $T_{3}$ were stable, but the TSH response on TRH declined. Ultimately in 1984 serum $T_{4}$ and $T_{3}$ came into the hyperthyroid range and the patient was advised to undergo surgery. Histological examination of the excised thyroid gland (1987) revealed nodular dysplasia.

\section{Discussion}

The development of hyperthyroidism in multinodular goitre is often insidious and without clinical symptoms, especially in older patients. Fluctuations in function have been described ${ }^{18-20}$ and may be caused by variable $T_{3}$ production in the thyroid $^{19}$ or by acute haemorrhagic infarction followed by degeneration of autonomous nodules. ${ }^{18,20}$ Parker et al. ${ }^{15}$ did a follow-up investigation in 36 patients with simple non-toxic goitre $11.5-16.0$ years after first presentation. Operations were mainly carried out in the first few years on

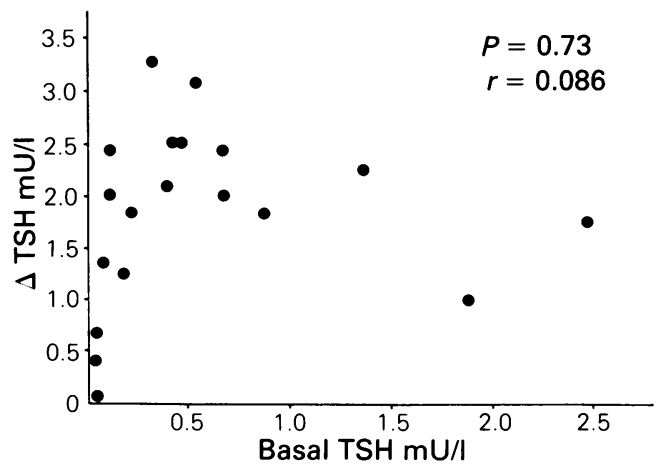

Figure 1 Correlation between basal TSH and $\triangle T$ TSH in patients with euthyroid autonomously functioning multinodular goitre (19 TRH tests in 16 patients; sensitive TSH-assay).

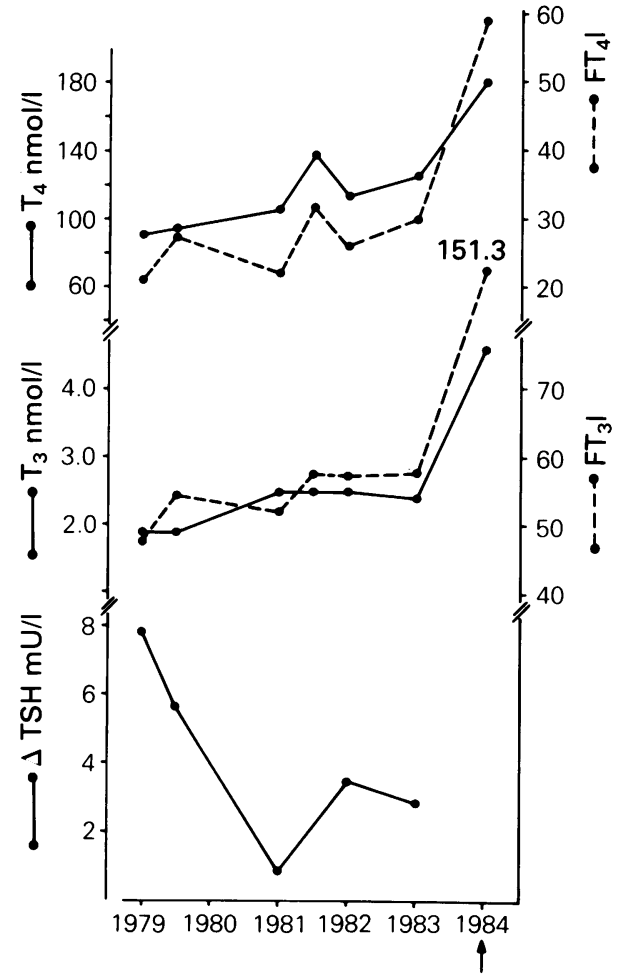

Figure 2 Course of thyroid function tests, including $\Delta$ TSH (TRH test) in a patient who demonstrated the whole functional cycle from non-autonomy (1979), through autonomy (1981) up to hyperthyroidism (1984) (see case report).

patients with nodular goitre ( 7 because of compression and 3 for a cold nodule). Thyrotoxicosis occurred in 5 patients over the whole follow-up period, mostly in patients with diffuse goitres. No investigations were performed to examine the existence of autonomy. Wiener ${ }^{17}$ reported that 4 patients of 28 with multinodular goitres and 8 of 46 with solitary or predominant autonomous nodules became hyperthyroid. TRH tests were performed but no comment was made whether the hyperthyroid patients originally had diminished TSH response to TRH.

In our 90 patients with euthyroid multinodular goitres 8 ( 1 with $T_{3}$ toxicosis) became hyperthyroid within 7 years and all of them had autonomous function before becoming hyperthyroid. In the first years of the study many patients were operated upon mainly for cosmetic reasons or were lost for follow-up; these patients are inevitably omitted from studies concerning the natural history. Most of the patients showed a relatively stable course and transitions in function in euthyroid patients were not frequently observed. Similar data were reported by Wiener. ${ }^{17}$ Because autonomy appears to be a prestage of hyperthyroidism, it is worth 
while to trace autonomous function. It might even be justified to treat especially those older patients who have cardiac problems in the stage of autonomy before they develop overt hyperthyroidism.

A follicular carcinoma was found (by chance) in only one patient. The incidence of carcinoma in a multinodular goitre has been reported to be as high as $13 \%,{ }^{21}$ but this was a retrospective study of a selected group of patients. Also, the association of malignancy and autonomous nodular goitre has been reported to be rare in Europe ${ }^{22}$ but not in the United States. ${ }^{7}$ Occult thyroid carcinoma has been reported to occur in $8.6 \%$ of the normal Swedish population. ${ }^{23}$ In formerly endemic goitre areas, on the other hand, $30 \%$ of carcinomas developed in large goitres of longstanding with impaired TSH response to TRH. ${ }^{24}$

Published data concerning mechanical complications of multinodular goitre are limited. Frey ${ }^{25}$ observed narrowing of the trachea by half in 16 and by two thirds in 8 of 49 patients with goitres grade II and III. No mention was made of complaints. Only seldom is it necessary for surgery because of mechanical complications.

One patient, who is described in more detail, deserves special attention. This female patient exhibited the whole natural course as hypothesized by many authors. To our knowledge, no such patient with multinodular goitre has been described before although Lerro et al. ${ }^{17}$ described 2 patients with a solitary nodule who exhibited a similar course. The natural history of multinodular goitre as suggested by transversal studies .11-14.26 $^{1.26}$ and as demonstrated in our patient is illustrated in Figure 3.

\section{References}

1. Miller, J.M. \& Block, M.A. Functional autonomy in multinodular goiter. $J A M A$ 1970, 214: 535-539.

2. Sokal, J.E. A long-term follow-up of nontoxic nodular goiter. Arch Int Med 1957, 99: 60-69.

3. Vander, J.B., Gaston, E.A. \& Dawber. Th.R. The significance of nontoxic thyroid nodules. Ann Int Med 1968, 69: 537-540.

4. Plummer, H.S. The clinical and pathological relationship of simple and exophthalmic goiter. Am J Med Sci 1913, 146: 790-795.

5. Cole, W.H., Slaughter, D.P. \& Rossiter, L.J. Potential dangers of nontoxic nodular goiter. JAMA 1945, 127: 883-888.

6. Blum, M., Shenkman, L. \& Hollander, C.S. The autonomous nodule of the thyroid: correlation of patient age, nodule size and functional status. Am J Med Sci 1975, 269: 43-50.

7. Hamburger, J.I. Solitary autonomously functioning thyroid lesions. Am J Med 1975, 58: 740-748.

8. Hamburger, J.I. Evolution of toxicity in solitary nontoxic autonomously functioning thyroid nodules. J Clin Endocrinol Metab 1980, 50: 1089-1093.

9. Belfiore, A., Sava, L., Runello, F., Tomaselli, L. \& Vigneri, R. Solitary autonomously functioning thyroid nodules and iodine deficiency. J Clin Endocrinol Metab 1983, 56: 283-287.

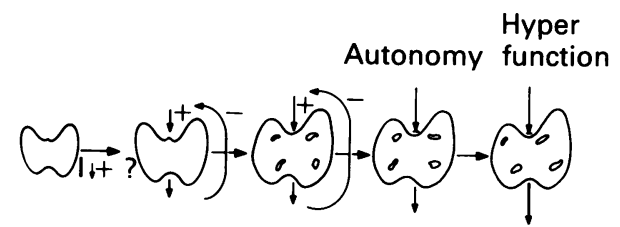

Figure 3 The natural history of goitre. As a result of iodine (I) deficiency and/or other factors a diffuse goitre develops, which becomes multinodular. Both function and regulation are normal then, but gradually autonomy comes about, with suppressed TSH production and slightly elevated serum $T_{4}$ and $T_{3}$ levels still within the normal range. Eventually frank hyperthyroidism develops with elevated serum $T_{4}$ and $T_{3}$ and suppressed TSH.

It has been suggested by several authors that with the advent of the sensitive TSH-assay the TRH test has become redundant. ${ }^{27-29}$ Our data from 19 TRH tests performed in 16 patients with subnormal TSH response to TRH show that there was no correlation between basal serum TSH and $\Delta \mathrm{TSH}$ and also that there was measurable, albeit impaired, TSH response to TRH. We agree with Kirkegaard and Bregengard ${ }^{30}$ that the TRH test may still be useful in patients with suspected euthyroid autonomous functioning (multinodular) goitres.

\section{Acknowledgement}

The authors thank Dr J. Hermans for assistance in statistical calculations and Mrs G. Lems for secretarial help.

10. Lerro, S., Losa, M., Trisorio, M.T. \& Liuzzi, A. Free thyroid hormone levels and TSH response to TRH in patients with autonomous thyroid adenomata and normal T3 and T4. Clin Endocrinol 1985, 23: 373-378.

11. Elte, J.W.F., Haak, A., Frölich, M., Wiards, K.S. \& van Wermeskerken, R.K.A. Autonomously functioning euthyroid multinodular goitre. Neth J Med 1977, 20: 1-4.

12. Smeulers, J., Docter, R., Visser, T.J. \& Hennememann, G. Response to thyrotrophin-releasing hormone and triiodothyronine suppressibility in euthyroid multinodular goitre. Clin Endocrinol 1977, 7: 389-397.

13. Emrich, D. \& Bähre, M. Autonomy in euthyroid goitre: maladaption to iodine deficiency. Clin Endocrinol 1978, 8: $257-265$

14. Hamburger, J.I. \& Hamburger, S.W. Diagnosis and management of large toxic multinodular goiters. $J$ Nucl Med 1985 , 26: $888-892$.

15. Parker, J.L.W., Ratcliffe, J.G. \& Alexander, W.D. Sporadic non-toxic goitre. Acta Endocrinol 1977, 85: 497-507.

16. Wiener, J.D. \& de Vries, A.A.A. On the natural history of Plummer's disease. Clin Nucl Med 1979, 3: 180-190. 
17. Wiener, J.D. Long-term follow-up in untreated Plummer's disease (autonomous goiter). Clin Nucl Med 1987, 12: 198-203.

18. Smeulers, J., Docter, R., Visser, T.J. \& Hennemann, G. Acute thyrotoxicosis in multinodular goitre. Neth J Med 1977, 20: 275-277.

19. Smeulers, J., Visser, T.J., Docter, R. \& Hennemann, G. Occasional thyroxine and triiodothyronine hypersecretion in euthyroid multinodular goitre. Neth $J$ Med 1980, 23: 152-154.

20. Hamburger, J.I. \& Taylor, C.I. Transient thyrotoxicosis associated with acute hemorrhagic infarction of autonomously functioning thyroid nodules. Ann Int Med 1979, 91: 406-409.

21. McCall, A., Jarosz, H., Lawrence, A.M. \& Paloyan, E. The incidence of thyroid carcinoma in solitary cold nodules and in multinodular goiters. Surgery 1986, 100: 1128-1132.

22. Wiener, J.D. \& Frensdorf, E.L. Thyroid autonomy (Plummer's Disease) with contralateral malignancy-mere coincidence? Acta Med Scand 1976, 200: 509-512.

23. Bondeson, L. \& Ljungberg, O. Occult thyroid carcinoma at autopsy in Malmö, Sweden. Cancer 1981, 47: 319-323.
24. Gemsenjäger, E., Heitz, Ph.U., Staub, J.J. \& Girard, J. Thyrotropin secretion in carcinoma of the thyroid. Surg Gynecol Obstet 1980, 151: 205-208.

25. Frey, W.K. Die Aufgaben der konventionellen Röntgendiagnostik der Schilddrüse. Akt Endokr Stoff w' 1983. 4: $2-8$.

26. Studer, H., Peter, H.J. \& Gerber, H. Toxic nodular goitre. Clin Endocrinol Metab 1985, 14: 351-372.

27. Seth, J., Kellett, H.A., Caldwell, G. et al. A sensitive immunoradiometric assay for serum thyroid stimulating hormone: a replacement for the thyrotrophin releasing hormone test? $\mathrm{Br}$ Med J 1984, 289: 1334-1336.

28. Kerr, D.J. \& Alexander, W.D. Is the TRH test usually unnecessary. Lancet 1984, ii: $1161-1162$ (letter).

29. Carayon, P., Martino, E., Bartalena, L. et al. Clinical usefulness and limitations of serum thyrotropin measurement by 'ultrasensitive' methods. Hormone Res 1987, 26: 105-117.

30. Kirkegaard, C. \& Brègengard, C. Is the TRH test necessary? Lancet 1985, i: 222 (letter). 